\title{
Correction to: Sustained and targeted episcleral delivery of celecoxib in a rabbit model of retinal and choroidal neovascularization
}

Luiz H. Lima', Michel E. Farah', Glenwood Gum², Pamela Ko ${ }^{3}$ and Ricardo A. Pontes de Carvalho ${ }^{3 *}$

\section{Correction to: Int J Retin Vitr (2018) 4:31}

https://doi.org/10.1186/s40942-018-0131-1

Following publication of the original article [1], the authors reported the following changes to the article:

1. The correct name of Dr. De Carvalho is Ricardo A. Pontes de Carvalho.

2. The corresponding author of the article has changed to Ricardo A. Pontes de Carvalho.

Email: rcarvalho@3tophthalmics.com

\section{Publisher's Note}

Springer Nature remains neutral with regard to jurisdictional claims in published maps and institutional affiliations.

Received: 5 September 2018 Accepted: 12 September 2018 Published online: 07 January 2019

\section{Reference}

1. Lima LH, et al. Sustained and targeted episcleral delivery of celecoxib in a rabbit model of retinal and choroidal neovascularization. Int J Retin Vitr. 2018;4:31. https://doi.org/10.1186/s40942-018-0131-1.

\section{Author details}

${ }^{1}$ Federal University of Sao Paulo, Rua Botucatu, 821, Vila Clementino, São Paulo, SP CEP: 04023-062, Brazil. ${ }^{2}$ Biological Test Center, Irvine, CA, USA. ${ }^{3}$ 3T Ophthalmics, Irvine, CA, USA. 